\title{
Hubungan Tingkat Osteoporosis Berdasarkan Indeks Singh dan Fraktur Leher Femur Akibat Low Energy Trauma di Beberapa Rumah Sakit di Padang Tahun 2016-2018
}

\author{
Wulandari Taradita ${ }^{1}$, Rizki Rahmadian ${ }^{2}$, Roni Eka Sahputra ${ }^{3}$
}

\begin{abstract}
Abstrak
Osteoporosis merupakan penurunan kepadatan tulang dan kerusakan mikro-arsitektur tulang yang menyebabkan tulang menjadi rapuh sehingga seringkali baru disadari apabila telah terjadi perubahan bentuk tulang ataupun fraktur, terutama fraktur leher femur dan panggul karena trauma. Indeks Singh adalah suatu metode untuk menilai osteoporosis menggunakan pola trabekula tulang di femur proksimal. Tujuan penelitian ini adalah mengetahui hubungan tingkat osteoporosis berdasarkan Indeks Singh dan fraktur leher femur akibat low energy trauma di beberapa Rumah Sakit di Padang tahun 2016-2018. Penelitian ini merupakan analitik dengan desain cross sectional. Sampel berupa 22 foto polos pelvis ( $x$-ray) pasien dari bagian rekam medis Poliklinik RSUP Dr. M. Djamil Padang dan RST Dr. Reksodiwiryo Padang dari Januari 2016 sampai April 2018. Hasil penelitian menunjukkan bahwa fraktur leher femur karena low energy trauma didominasi oleh perempuan $(72,7 \%)$ dan usia diatas 70 tahun $(45,5 \%)$. Tingkat osteoporosis berdasarkan indeks Singh terbanyak pada grade A $(40,9 \%)$ dan mayoritas fraktur leher femur pada klasifikasi Garden tipe $4(77,3 \%)$. Tidak terdapat hubungan yang bermakna antara tingkat osteoporosis berdasarkan indeks Singh dengan fraktur leher femur akibat low energy trauma $(p=0,483)$.
\end{abstract}

Kata kunci: osteoporosis, fraktur leher femur, indeks singh, klasifikasi Garden

\section{Abstract}

Osteoporosis is a decreasing of the bone mass density and a micro-architecture damage that cause the bones fragile and usually realized when bone deformities or fractures occur, especially neck femur and hip fractures caused by traumas. Singh Index is a method to measure osteoporosis using bone's trabeculae pattern of proximal femur.The objective of this study was to know the correlation between the osteoporosis levels based on Singh Index and neck femur fractures caused by low-energy trauma in some hospitals in Padang in 2016-2018. This study was analytical with cross sectional design. Sample size were 22 samples of patients' $x$-ray images from medical record and policlynic of RSUP Dr. M. Djamil and RST Dr. Reksodiwiryo Padang from January 2016 until April 2018. This study showed that neck femur fractures caused by low energy trauma occured mostly in women (72,7\%) and people older than 70 years old (45,5\%). The osteoporosis levels based on Singh Index occured mostly in grade A (40,9\%) and neck femur fractures with the classification of Garden type 4 in majority $(77,3 \%)$. There were no significant correlation between the osteoporosis levels based on Singh Index and neck femur fractures caused by low-energy trauma $(p=0,483)$.

Keywords: osteoporosis, neck femur fractures, Singh index, classification of Garden

Affiliasi penulis: 1. Prodi Kedokteran Fakultas Kedokteran Universitas Andalas Padang (FK Unand), 2. Bagian Ortopedi FK Unand/RSUP Dr. M. Djamil Padang, 3. Bagian Ortopedi FK Unand/RSUP Dr. M. Djamil Padang

Korespondensi: Wulandari Taradita, Email: wulantardit@gmail.com Telp: 082112409854

\begin{abstract}
PENDAHULUAN
Osteoporosis merupakan gangguan pada tulang yang ditandai dengan penurunan kepadatan tulang dan kerusakan mikro-arsitektur tulang yang menyebabkan tulang menjadi rapuh. ${ }^{1}$ Osteoporosis
\end{abstract}


dibagi atas: 1. primer akibat usia lanjut (Senilis) dan wanita post-menopause, 2 . sekunder yang didapat dari faktor lain seperti penggunaan kortikosteroid berkepanjangan, penyakit kronis, dan lain-lain. ${ }^{2}$

Osteoporosis dikenal juga dengan sebutan "silent thief" atau "silent disease" yang seringkali tanpa gejala dan baru diketahui saat telah terjadi fraktur. ${ }^{3}$ Penyebab trauma pada fraktur yang menjadi masalah kesehatan dunia adalah akibat jatuh dan diikuti dengan kecelakaan lalu-lintas. ${ }^{4}$

Ada empat cara tulang bereaksi dengan kondisi abnormal, yaitu kematian lokal, perubahan deposisi tulang, perubahan resorpsi tulang dan kegagalan mekanik atau fraktur. Fraktur atau patah tulang merupakan suatu gangguan pada diskontinuitas tulang, tulang rawan atau sendi, dan lempeng epifisis. Diskontinuitas tulang tersebut dapat terjadi karena tekanan dari luar yang datang lebih besar dari yang dapat ditahan tulang. ${ }^{5}$

Fraktur panggul akibat kerapuhan atau fragility hip fractures yang termasuk di dalamnya fraktur trochanter dan juga fraktur leher femur merupakan akibat paling serius dari osteoporosis. ${ }^{6}$ Fraktur leher femur adalah keadaan rusaknya atau terputusnya hubungan leher femur yang disebabkan oleh trauma. Trauma pada daerah trokanter dengan panggul pada posisi fleksi dan rotasi, baik karena kecelakaan lalulintas ataupun jatuh terpeleset dan terduduk merupakan penyebab tersering pada usia lanjut. ${ }^{7}$

Pada dewasa muda terdapat dua mekanisme utama terjadinya fraktur leher femur. Mekanisme tersebut antara lain, trauma langsung dengan energi tinggi (high energy trauma) yang mengenai tulang leher femur pada pasien sehat dan trauma dengan energi yang relatif rendah (low energy trauma) pada pasien dengan penyakit predisposisi, alkoholisme atau hasil awal dari demineralisai terkait kerapuhan tulang. ${ }^{8}$

Hubungan fraktur leher femur dengan osteoporosis terutama pada wanita post-menopause telah mendorong peningkatan pengetahuan dalam skrining untuk osteoporosis dan profilaksis dalam populasi berisiko. ${ }^{9}$ Penelitian oleh Gulati et al di India pada tahun 2010 menunjukkan bahwa terdapat 60\% penderita osteoporosis yang mengalami fraktur femur proksimal. $^{10}$ Penelitian di Solo pada tahun 2016 mengenai perbandingan kasus osteoporosis pada fraktur intertrochanter femur dan fraktur leher femur pada wanita usia lanjut didapatkan hasil seimbang, yaitu terdapat 32 pasien osteoporosis pada masingmasing fraktur yang diambil dari 64 sampel penelitian. $^{11}$

Teknik diagnosis dari pasien fraktur leher femur yang menderita osteoporosis dapat dimulai dari anamnesis, pemeriksaan fisik, hingga pemeriksaan kepadatan tulang dengan berbagai macam alat seperti DEXA (Dual Energy X-ray Absorptiometry), serta dengan menggunakan foto polos pelvis atau $X$-Ray. ${ }^{12}$ DEXA merupakan golden standard dalam mengukur kepadatan atau densitas tulang, namun pemeriksaan ini masih tergolong mahal. Maka digunakanlah metode konvensional yaitu dengan melihat tingkat osteoporosis menggunakan indeks Singh pada foto polos pelvis. $^{13}$

Indeks Singh adalah suatu metode untuk menilai osteoporosis menggunakan pola radiologi dan densitas trabekula tulang di femur bagian proksimal. Analisis morfometri dan gambaran histologi menunjukkan bahwa berkurangnya kepadatan tulang ditandai oleh berubahnya pola trabekulasi femur bagian proksimal pada foto polosproyeksi anterior posterior pelvis. Berdasarkan pada penemuannya, maka indeks Singh dibagi menjadi beberapa tingkat, mulai dari tingkat 1 (hanya stuktur dasar trabekula yang terlihat, densitas tulang rendah) sampai dengan tingkat 6 (seluruh struktur trabekula terlihat, densitas tulang tinggi). ${ }^{14}$

Indeks Singh dapat digunakan untuk deteksi dini osteoporosis dan memprediksi risiko terjadinya fraktur leher femur pada populasi berisiko tinggi meskipun realibilitas dan keakuratan dari indeks ini masih menuai kontroversi jika dibandingkan dengan DEXA. ${ }^{15}$ Berdasarkan penjelasan tersebut, maka peneliti berkeinginan untuk melakukan penelitian mengenai Hubungan Tingkat Osteoporosis berdasarkan Indeks Singh dengan Fraktur Leher Femur akibat Low Energy Trauma di Beberapa Rumah Sakit di Padang Tahun 2016-2018. 


\section{METODE}

Penelitian ini merupakan studi analitik dengan pendekatan cross sectional. Populasi untuk penelitian ini adalah foto polos pelvis pasien fraktur leher femur yang didapat dari catatan rekam medis pasien Poliklinik RSUP Dr. M. Djamil Padang dan RST Dr. Reksodiwiryo Padang pada Januari 2016 sampai April 2018, yang dilaksanakan pada Desember 2017-Mei 2018.

Sampel penelitian berjumlah 22 sampel yang dipilih dari seluruh populasi yang sesuai dengan kriteria inklusi hingga jumlah yang dibutuhkan terpenuhi. Kriteria inklusi yaitu rekam medis lengkap pasien fraktur leher femur berusia diatas 30 tahun, foto polos pelvis pasien fraktur leher femur yang memiliki kelengkapan data sesuai dengan rekam medis pasien, dan bersedia meminjamkan foto polos pelvis. Kriteria eksklusi yaitu foto polos pelvis pasien fraktur leher femur yang tidak terbaca, pasien yang tidak dapat dihubungi untuk peminjaman foto polos pelvis, foto polos pelvis pasien yang mengalami fraktur leher femur bilateral atau penyakit tulang lainnya dan foto polos pelvis pasien fraktur leher femur akibat high energy trauma.

Data yang dikumpulkan adalah data sekunder berupa foto polos pelvis pasien yang diperoleh dari catatan rekam medis atau catatan poliklinik rumah sakit yang telah ditentukan. Peneliti kemudian menghubungi pasien untuk meminjam foto polos pelvis, selanjutnya foto polos pelvis tersebut diinterpretasikan sebagai hasil penelitian yaitu indeks Singh dan klasifikasi Garden.

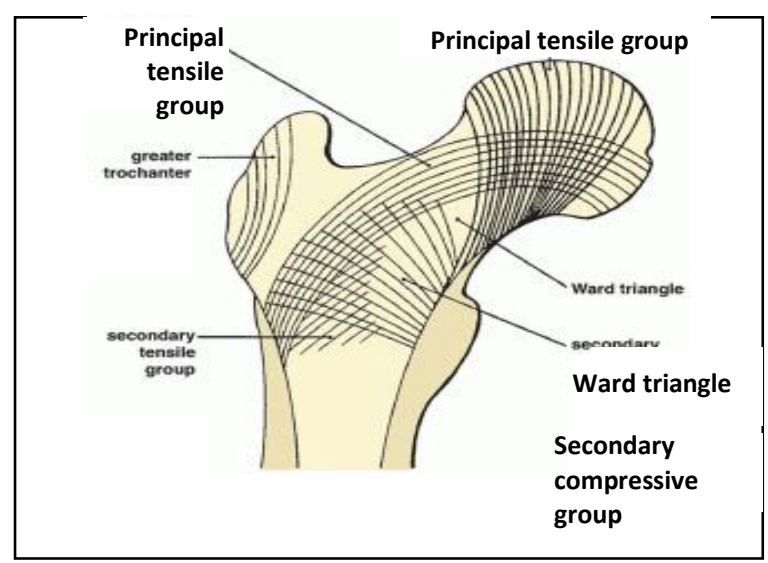

Gambar 1. Pola trabekula normal pada Indeks Singh. ${ }^{18}$
Interpretasi dilakukan oleh peneliti dengan bantuan dokter spesialis Ortopedi atau Radiologi. Data sekunder tersebut kemudian diolah secara komputerisasi.

Analisis data yang dilakukan adalah analisis univariat dan bivariat. Analisis univariat digunakan untuk mendeskripsikan karakteristik setiap variabel penelitian antara lain usia, jenis kelamin, jenis fraktur leher femur, dan tingkat osteoporosis.yang digunakan dengan menggunakan tabel distribusi frekuensi. Analisis bivariat digunakan untuk menilai atau menguji hipotesis antar dua variabel yang akan diketahui hubungannya, yaitu tingkat osteoporosis dengan fraktur leher femur. Uji yang digunakan adalah uji Kruskal wallis yang merupakan alternative dari uji Chi square. Variabel dianggap memiliki hubungan yang bermakna atau signifikan apabila nilai $p<0,05$.

\section{HASIL}

Penelitian ini dilakukan di bagian rekam medis dan Poliklinik RSUP Dr. M. Djamil Padang dan RST Dr. Reksodiwiryo Padang. Data awal yang diperoleh peneliti berjumlah 25 rekam medis dan 11 data pasien kontrol di poliklinik. Dari jumlah tersebut didapatkan 22 foto polos pelvis yang memenuhi kriteria inklusi dan menjadi sampel penelitian.

Tabel 1. Distribusi frekuensi karakteristik pasien fraktur leher femur akibat low energy trauma di RSUP Dr. M. Djamil Padang dan RST Dr. Reksodiwiryo Padang berdasarkan usia dan jenis kelamin

\begin{tabular}{llcc}
\hline No & Karakteristik & $\mathbf{f}$ & $\%$ \\
\hline 1 & Usia & 0 & 0 \\
& $31-40$ tahun & 1 & 4,5 \\
& $41-50$ tahun & 5 & 22,7 \\
& $51-60$ tahun & 6 & 27,3 \\
& $61-70$ tahun & 10 & 45,5 \\
& $>70$ tahun & 22 & $100 \%$ \\
\hline 2 & Total & & \\
& Jenis Kelamin & 6 & 27,3 \\
& Laki-laki & 16 & 72,7 \\
\hline & Perempuan & 22 & $100 \%$ \\
\hline
\end{tabular}


Berdasarkan Tabel 1 dapat dilihat bahwa sampel terbanyak berusia lebih dari 70 tahun yaitu sebanyak 10 orang (45,5\%), sebagian kecil berusia 61-70 tahun (27,3\%), beberapa berusia 51-60 tahun $(22,7 \%)$, lainnya berusia $41-50$ tahun $(4,5 \%)$, dan tidak ada usia 31-40 tahun. Sampel terdiri dari sebagian besar perempuan $(72,7 \%)$ dan beberapa laki-laki $(27,3 \%)$.

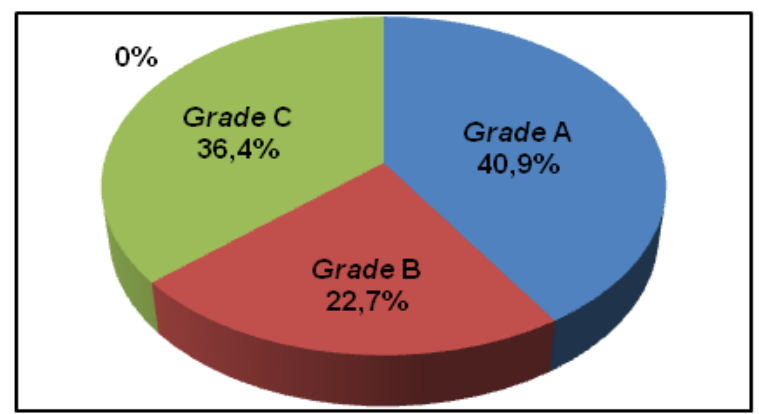

Gambar 2. Distribusi frekuensi tingkat osteoporosis pasien fraktur leher femur akibat low energy trauma berdasarkan Indeks Singh

Penelitian ini memperoleh data bahwa hampir sebagian dari sampel (40,9\%) dikelompokkan dalam grade A (Indeks Singh tingkat 4-5), sebagian kecil dari sampel $(36,4 \%)$ dikelompokkan dalam grade C (indeks Singh tingkat 1-2), dan beberapa dari sampel (22,7\%) dikelompokkan dalam grade B (Indeks Singh tingkat 3).

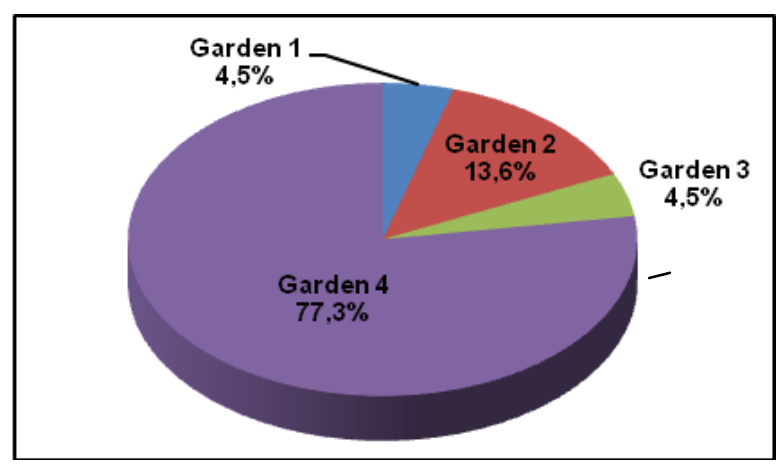

Gambar 3. Distribusi frekuensi pasien fraktur leher femur akibat low energy trauma berdasarkan klasifikasi Garden

Penelitian ini memperoleh data bahwa sebagian besar responden $(77,3 \%)$ dikelompokkan dalam klasifikasi Garden tipe 4, sebagian kecil dari responden (13,6\%) dikelompokkan dalam klasifikasi Garden tipe 2, dan beberapa responden (4,5\%) masing-masing dikelompokkan dalam klasifikasi Garden tipe 1 dan 3.

Tabel 2. Hubungan tingkat osteoporosis dengan fraktur leher femur akibat low energy trauma

\begin{tabular}{cccccc}
\hline Tingkat & \multicolumn{3}{c}{ Fraktur Leher Femur } & \multirow{2}{*}{ p } \\
\cline { 2 - 5 } Osteo- & Tipe 1Tipe 2Tipe 3Tipe 4 & \\
\cline { 2 - 5 } porosis & $\%$ & $\%$ & $\%$ & $\%$ & \\
\hline Grade A & 4,5 & 9,1 & 0,0 & 27,3 & \\
Grade B & 0,0 & 4,5 & 0,0 & 18,2 & 0.483 \\
Grade C & 0,0 & 0,0 & 4,5 & 31,8 & \\
\hline Total & 4,5 & 13,6 & 4,5 & 77,3 & \\
\hline
\end{tabular}

${ }^{\text {*Kruskal wallis test }}$

Data dalam tabel diatas pada awalnya dianalisis dengan uji Chi-square, namun karena tidak memenuhi syarat uji maka digunakan uji alternatif Kruskal wallis. Hasil menunjukkan sebagian besar responden mengalami osteoporosis grade C (indeks Singh tingkat 1-2) dengan fraktur leher femur tipe 4 klasifikasi Garden dengan nilai $p=0,483(p>0,05)$. Berdasarkan hasil tersebut dapat disimpulkan secara statistik bahwa tidak terdapat hubungan yang bermakna (signifikan) antara tingkat osteoporosis berdasarkan indeks Singh dengan fraktur leher femur akibat low energy trauma di beberapa rumah sakit di Padang tahun 2016-2018.

\section{PEMBAHASAN}

\section{KarakteristikSampel Penelitian}

Karakteristik sampel penelitian berdasarkan usia didapatkan frekuensi terbanyak pada usia diatas 70 tahun. Hal ini tidak jauh berbeda dengan penelitian di Solo tahun 2016 yang mendapatkan raerata usia pasien fraktur leher femur yaitu 72,5 $\pm 5,8$ tahun. $^{11}$ Peningkatan usia, massa tulang rendah, dan riwayat fraktur sebelumnya dapat berpengaruh terhadap kejadian fraktur, terutama tulang panggul. ${ }^{16}$ Usia lanjut juga seringkali mengalami lemah otot dan hilang keseimbangan sehingga mengakibatkan peningkatan kecenderungan untuk jatuh. $^{9}$

Berdasarkan jenis kelamin didapatkan perempuan lebih banyak dibanding laki-laki. Hal ini sesuai dengan penelitian yang dilakukan di Royal 
Infirmary of Edinburg, Inggris tahun 2010/11 mengenai fraktur akibat jatuh, yaitu 40,7\% pada pria dan $80,7 \%$ pada wanita. ${ }^{17}$ Alasan utama hal ini yaitu wanita sering dikaitkan dengan osteoporosis post-menopause oleh penurunan hormon estrogen sehingga menyebabkan

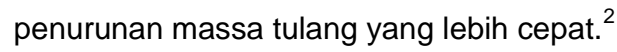

\section{Tingkat Osteoporosis Pasien Fraktur Leher} Femur akibat Low Energy Trauma berdasarkan Indeks Singh

Penelitian ini menunjukkan hasil Grade A yang terbanyak atau tingkat osteoporosis berdasarkan Indeks Singh 4 sampai 5 pada pola trabekula tulang leher femur. Hal ini sesuai dengan penelitian di India pada tahun 2006/7 yang menunjukkan hasil Grade A merupakan tingkat osteoporosis terbanyak pada wanita post-menopause, yaitu $41,7 \%$ pada femur proksimal kiri dan $42,7 \%$ pada femur proksimal kanan. $^{18}$

Penelitian tentang faktor yang memengaruhi tingkat osteoporosis seseorang menyebutkan bahwa kurangnya asupan kalsium merupakan salah satu penyebab osteoporosis. ${ }^{19}$ Penelitian lainnya menyebutkan bahwa setiap jenis kelamin memiliki faktor yang berbeda untuk risiko terjadinya osteoporosis. Aktivitas fisik, asupan nutrisi dan usia merupakan faktor determinan pada laki-laki, sedangkan pada perempuan, selain faktor yang ada pada laki-laki terdapat faktor lain seperti menopause dan penggunaan kontrasepsi. ${ }^{20}$

\section{Fraktur Leher Femur akibat Low Energy Trauma berdasarkan Klasifikasi Garden}

Fraktur leher femur akibat low energy trauma paling banyak pada penelitian ini yaitu klasifikasi Garden tipe 4 yang merupakan fraktur dengan displaced atau mengalami pergeseran total. Fraktur impaksi, dislokasi dan fraktur displaced dapat terjadi karena tekanan pada tulang dapat berupa tekanan sepanjang aksis tulang serta trauma karena tarikan pada ligamen atau tendon akan menarik sebagian tulang. ${ }^{9}$

Trauma minimal seperti jatuh terduduk akan berbeda dengan jatuh terpeleset atau dengan kecepatan gaya yang tinggi dan beban yang lebih tinggi. Hasil penelitian di Jakarta terhadap wanita usia $\geq 50$ tahun menunjukkan bahwa terdapat korelasi antara nilai Indeks Massa Tubuh dengan risiko fraktur osteoporosis leher femur berdasarkan perhitungan FRAX® tool. $^{21}$ Trauma berulang dan tidak ditangani secara cepat dan tepat juga dapat menyebabkan derajat fraktur menjadi lebih tinggi. Hal ini disebut juga dengan neglected fracture yang mana pada klasifikasi Garden tahap 1 dapat berujung ke tahap 4 apabila tidak segera ditatalaksana. ${ }^{9}$ Penelitian yang dilakukan di Jawa Timur mendapatkan hasil dari 26 orang penderita, sebagian besar $(69,23 \%)$ pasien mengalami neglected fracture di ektremitas bawah, terutama femur $(38,46 \%)$. Malunion dan nonunion merupakan komplikasi yang tersering ditemukan (masing-masing $46,15 \%)^{22}$

\section{Hubungan Tingkat Osteoporosis berdasarkan Indeks Singh dengan Fraktur Leher Femur Akibat Low Energy Trauma}

Data pada Tabel 2 menunjukkan bahwa pada tingkat osteoporosis yang tinggi (tingkat 1-2) atau Grade C banyak terjadi fraktur leher femur dengan derajat tinggi (Garden tipe 4). Hasil uji statistik menunjukkan bahwa tidak terdapat hubungan yang bermakna (signifikan) antara tingkat osteoporosis berdasarkan Indeks Singh dengan fraktur leher femur akibat low energy trauma. Hasil ini disimpulkan karena nilai signifikasi atau $\mathrm{p}$ lebih dari 0,05.

Risiko terjadinya hal tersebut dapat dikarenakan oleh ketahanan dan kelenturan tulang saat terjadinya trauma, serta frekuensi trauma. Semakin lentur tulang seseorang maka akan semakin rendah risiko terjadinya fraktur. Pada usia lanjut yang sebelumnya pernah mengalami fraktur tipe apapun, maka risiko untuk terjatuh dan mengalami fraktur yang lebih berat meningkat. $^{23}$

Pada umumnya fraktur sering terjadi pada tulang yang memiliki banyak trabekula, yaitu pergelangan tangan (wrist), tulang belakang (spine), dan pangkal paha (femur). ${ }^{24}$ Trabekula memiliki elastisitas yang lebih rendah dari tulang korteks dan berbeda jumlahnya pada setiap individu. ${ }^{25}$ Perbedaan kualitatif dalam struktur tulang ini juga merupakan salah satu alasan lainnya, bahkan diantara orang 
dengan massa tulang sama, yang memiliki interkonektivitas trabekula lebih besar akan mengalami fraktur lebih mudah. ${ }^{9}$

\section{SIMPULAN}

Tidak terdapat hubungan yang bermakna antara tingkat osteoporosis berdasarkan indeks Singh dengan fraktur leher femur akibat low energy trauma.

\section{DAFTAR PUSTAKA}

1. Dennis KB, Ninay K. Sistem muskuloskeletal. Dalam: Robbins, Kumar, Cotran. Buku Ajar Patologi Edisi ke-7 Vol 2 (terjemahan). Jakarta: EGC; 2007.hlm.846.

2. Keating JF, Grant A, Masson M, Scott NW, Forbes JF. Randomized comparison of reduction and fixation, bipolar hemiarthroplasty, and total hip arthroplasty.Treatment of displaced intracapsular hip fractures in healthy older patients. J Bone Joint Surg Am. 2006;88(2):249-60.

3. World Health Organization (WHO). Prevention and management of osteoporosis: report of a WHO scientific group. World Health Organ Tech Rep Ser. 2003;921:1-164.

4. World Health Organization (2017). FALLS. (diunduh 20 September 2017). Tersedia dari: http://www.who.int/en/news-room/fact-sheets/ detail/falls

5. Salter RB. Textbook of disorders and injuries of the musculoskeletal system. Edisi ke-3. Baltimore: Lippincott Williams and Wilkins; 1999.hlm.29-33.

6. Cummings SR, Melton LJ. Epidemiology and outcomes of osteoporotic fractures. Lancet. 2002;359(9319):1761-7.

7. Helmi ZN. Buku Ajar Gangguan Muskuloskeletal Edisi Kedua. Jakarta: Salemba Medika; 2013.hlm. 506-7.

8. Pauyo T, Drager J, Albers A, Harvey EJ. Management of femoral neck fractures in the young patient: A critical analysis review. World $\mathrm{J}$ Orthop. 2014;5(3):204-17.

9. Solomon L, Warwick D, Nayaga S. Apley's System of Orthopaedics and Fractures. Edidi ke-9. London: Hodder Arnold an Hachette UK Comp; 2010.hlm.19-853.
10. Gulati D, Kumar S, Arora A, Aggarwal AN, Bhargava SK. Bone mineral density in young Indian adults with traumatic proximal femoral fractures. A case control study. Acta Orthop Belg. 2010;76(3):335-40.

11. Ash $A B$. Studi komparasi modified singh index pada kasus fraktur collum femur dan fraktur intertrochanter femur pada pasien wanita geriatri (tesis). Solo: Fakultas Kedokteran Universitas Sebelas Maret; 2016.

12. Junaidi I. Pengenalan pencegahan serta pengobatan penyakit osteoporosis dan penyakit tulang lain yang mirip. Jakarta: PT Bhuana IImu Populer. 2009.hlm.2-36.

13. Soontrapa S. Modified Singh index in diagnosing femoral neck osteoporosis. J Med Assoc Thai. 2011;94(5):79-83.

14. Singh M, Nagrath AR, Maini PS. Changes in trabecular pattern of the upper end of the femur as an index of osteoporosis. J. Bone Joint Surg. 1970;52:457-67.

15. Julka A, Shrivastava S, Pandey R, Bhargav $P$ Ajmera A. To Evaluate the utility of Singh Index as an Indicator of osteoporosis and a predictor of fracture neck femur. Journal of Anatomical Society of India. 2012;61(2):192-8.

16. Kristine E. Epidemiology of fracture risk with advancing age. The Journals of Gerontology: Series A. 2013;68(10):1236-42.

17. Court-Brown CM, Clement ND, Duckworth AD, Biant LC, McQueen MM. The changing epidemiology of fall-related fractures in adults. Injury, Int. J. Care Injured. 2017;48(4):819-24.

18. Shankar VV, Jayanthi V, Srinath MG, Kulkarni R. A radiological study on the trabecular pattern in the upper end of the femur in post-menopausal women. J Clin Diagn Res. 2013;7(1):6-10.

19. Hermastuti, Arofani, Isnawati, Muflihah. Hubungan indeks massa tubuh, massa lemak tubuh, asupan kalsium, aktivitas fisik dan kepadatan tulang pada wanita dewasa muda. Journal of Nutrition College. 2012;1(1):63-71.

20. Prihatini S, Mahirawati VK, Jahari AB, Sudirman H. Faktor Determinan risiko osteoporosis di tiga Provinsi di Indonesia. Media Litbang Kesehatan. 2010;20(2):91-9. 
21. Nashirin AK, Zaki A, Nurmilasari, Widjajakusumah D, Fadhilah M. Hubungan Nilai indeks massa tubuh dengan nilai risiko fraktur osteoporosis berdasarkan perhitungan Frax® Tool pada wanita usia $\geq 50$ tahun di klub bina lansia Pisangan Ciputat tahun 2015. JMI. 2015; 12(2):190-3.

22. RSUD dr. Abdoer Rahem. Spektrum Penderita neglected fracture di RSUD dr. Abdoer Rahem dari Januari 2012 s/d Desember 2013. RSUD dr. Abdoer Rahem, Situbondo, Jawa Timur ; 2015 (diunduh 27 April 2018). Tersedia dari
http://kalbemed.com/Portals/6/07 225Spektrum\%2

OPenderita\%20Neglected\%20Fracture\%20di\%20R

SUD\%20dr.\%20Abdoer\%20RahemJanuari\%20201

2\%20sd\%20Desember\%202013.pdf

23. Arden N. Osteoporosis: risk fractors of fractures. Edisi ke-2. London: Remedica; 2006.hlm.55-7.

24. Adams JE. Medical radiology: diagnostic imaging and radiation oncology: dual-energy X-Ray absorptiometry. Heidelberg: Spinger; 2008. hlm.105-24.

25. Steele DG, Bramblet CA. The Anatomy and Biology of Human Skeleton. Texas: Texas A \& M University Press; 1988.hlm.10-4. 